\title{
Understanding success factors for ERP implementation: An integration of literature and experience
}

\author{
Angela R. Stone, University of North Alabama, astone1@una.edu \\ Xihui Zhang, University of North Alabama,xzhang6@una.edu
}

\begin{abstract}
Enterprise resource planning (ERP) solutions are a vital part of present-day organization's success. Most organizations at some point will choose to implement a new ERP system, which will present many challenges to all organizational employees from top to bottom. In order to ensure the success of a project of this magnitude, organizations should be aware of critical factors that can affect a successful implementation. Current literature identifies factors critical to the success of ERP implementations, but offers no consensus on which factors have the most impact. This paper provides a framework for organizations to ensure a successful ERP implementation by providing five key success factors based on literary research and real-life experiences. The research findings in this paper provide a unique perspective on successful implementation factors for chief information officers (CIOs) and information technology (IT) directors who are looking to implement ERP systems in the future.
\end{abstract}

Keywords: enterprise resource planning (ERP) systems, change management, data validation, silo effect, implementation, crosswalk

\section{Introduction}

Enterprise resource planning (ERP) systems have become an essential part of organizational infrastructure, allowing companies to effectively manage the execution of their entire business processes. Prior to ERP systems, functional departments suffered from the silo effect, operating within themselves and their own business processes without much consideration for other functional areas and their processes. ERP systems break this silo effect with integrated modules that allow users to perform cross-functional business processes in one integrated system with a centralized database (Mutsaddi, 2020).

ERP systems are critical to the success of today's organizations and can become a competitive advantage for some. Pabedinskaite (2010) suggested that ERP systems had become such an integral part of organizations that the majority would not be able to function without them. The advantages of ERP systems have allowed them to become a cornerstone to competitive business strategy, therefore more and more organizations have made investing in ERP systems a top priority in information technology spending (Biel, 2020; Tan et al., 2020).

The ERP market continues to grow with fifty percent of companies planning to acquire an ERP system or upgrade their existing ERP system (Biel, 2020); therefore, most organizations will undergo an ERP implementation at some point in the future. ERP implementations are a huge undertaking and require significant resources, commitment from the organization, and a clear vision of the ERP system that will best fit their needs. The monetary resources alone can total millions of dollars.

ERP implementations often fail when the organization or its employees are not committed to following through with the resources required to overcome the challenges encountered along the way (Chaudhry, 


\section{Issues in Information Systems}

Volume 22, Issue 2, pp. 146-156, 2021

2018; Jordan, 2018). It is estimated that seventy-five percent of ERP implementations fail (Jordan, 2018) which means organizations stand to lose valuable time and money invested in ERP projects. For this reason, organizations and consultants spend a great deal of time on factors critical to the success of implementations such as planning, defining the project scope, project budget, and project timeline.

However, there are additional key factors that are just as critical to the success or failure of an ERP implementation. Organizations should also be committed to project buy-in, change management, adequate employee training, employee participation, and data validation. Ignoring these key factors of ERP implementation will lead to failure of the project.

While theoretical and empirical literature have provided a multitude of potential critical success factors for ERP implementations over the years, there has been no consensus on which factors are most impactful on the implementation. The purpose of this research is to identify those additional critical success factors based not only on the current literature, but also on our own working experience from managing multiple ERP implementations. The research findings will provide a framework of critical success factors for organizations to take into account when considering an ERP implementation.

\section{Literature review}

\section{ERP systems are becoming more important}

ERP systems break the silo effect that afflicted legacy systems for years. Mutsaddi (2020) explains that to overcome the silo effect, organizations are implementing ERP systems that eliminate inefficiencies by integrating cross-functional business processes in a centralized database. ERP solutions are one of the mission-critical information systems for organizations because of their ability to integrate processes and data, eliminating the need to share information from various internal and external data sources, and making this information available to the organization's stakeholders in real time (Sternad \& Bobek, 2012).

ERP solutions have become a vital part of competitive business strategies for today's organizations. Pabedinskaite (2010) establishes the importance of ERP solutions for present day businesses which allow them to streamline processes, making them more efficient and creating a way for organizations to prosper in uncertain economic times. Not only do ERPs create efficiencies in operations, but they can also increase productivity (Kiran \& Reddy, 2019).

The demand for ERP systems does not appear to be slowing down any time soon. Biel (2020) states that the ERP market will continue to expand rapidly with the total market size expected to exceed $\$ 49.5$ billion by 2024 . Biel (2020) also states that at least $50 \%$ of companies are expected to upgrade or acquire an ERP system in the near future.

\section{Factors for ERP implementation}

The literature includes factors that are common for both implementation failure and implementation success. Momoh et al. (2010) found nine key factors that are critical in the failure of ERP implementation, including excessive customization, dilemma of internal integration, poor understanding of business implications and requirements, lack of change management, poor data quality, misalignment of IT with business, hidden costs, limited training, and lack of top management support. Implementation failures are not uncommon. According to Jordan (2018), up to 75\% of ERP implementations fail. Jordan suggests this is due to common misconceptions about ERPs, but can be avoided when considering the lessons to be learned from past failures. Other studies have shown less than 10\% of ERP implementations are successful, 


\section{Issues in Information Systems}

Volume 22, Issue 2, pp. 146-156, 2021

indicating that ERP implementations are more likely to fail than succeed and the larger the ERP project, the greater the risk of failure (Momoh et al., 2010). Saxena and McDonagh (2019) argue that most failure rates are associated with project time and budget overruns and suggest that the failure rate is overstated when considering the longevity of ERP system use. Pabedinskaite (2010) describes the implementation process as complex and suggests factors other than technical can also influence the results. To overcome the complexities of ERP implementation, a thoughtful and strategic approach can make the difference between a successful or failed implementation.

\section{Scope control}

According to Vayyavur (2015), it is critical that the project has clearly defined goals and objectives to ensure a successful implementation. Clear and measurable goals allow the team to focus on key issues, ensuring project's tasks are completed in a timely manner, while also providing a way to evaluate the work of the project's team (Pabedinskaite, 2010). A poorly defined scope can lead to essential solutions that are needed, but fall outside "the scope of the project," ultimately affecting the project budget and timeline. An inadequate project definition presents a risk to the organization that is often difficult to overcome, which is why most organizations and consultants spend a great deal of time on the project definition to ensure nothing is overlooked. Kiran and Reddy (2019) add that completing the project on time influences the success or failure of the implementation due to financial issues caused by delays.

\section{Human factors}

Human factors also play a significant role in failed ERP implementations. The results of the study by Chatzoglou et al. (2016) suggest that the organization should focus on the following six factors: top management support, organizational culture, vendor support, training, user involvement, and business process reengineering. Inadequate training and lack of employee participation pose as great a risk to success or failure as inadequate project definition. Amini and Safavi (2013) found that inadequate training and education of users during the implementation was a risk for failure, however, proper training and education was an important part of user adoption and satisfaction of the ERP. Guimaraes et al. (2015) encourage managers to take more seriously the importance of user training to increase the success of ERP implementation. They determined that training users and increasing their knowledge of ERPs facilitate better communication because they are better able to convey their needs to developers and also better able to understand the technical terms used by developers. Their study also determined that user involvement, along with management support, developer skills, and user training, has a direct impact on end-user jobs.

\section{Top management support}

Support from top management is included in numerous literature as one of the most significant factors that contribute to a successful ERP implementation. Chatzoglou et al. (2016) include top management support as one of six factors that contribute to a successful implementation as the literature suggests it is needed due to the financial resources required. Guimaraes et al. (2015) state it is an important factor because of the positive impact it creates on end-user jobs. Pabedinskaite (2010) states top management support is needed to create a favorable environment for the implementation, while also suggesting that top executives should participate in the implementation and not relegate themselves to mere observers. Amini and Safavi (2013) agree with top management participation and claim their support is needed to establish clear goals and objectives. Top management support is needed for all of these reasons, but also to set the tone for the project. Employees generally follow the lead of top management; therefore, they need to observe buy-in from them in order to fully commit themselves to the project. 


\section{Issues in Information Systems}

Volume 22, Issue 2, pp. 146-156, 2021

\section{Change management}

Managing change is a significant factor in ERP implementations and begins with managing employees' attitude toward change. Chaudhry (2018) suggests that employee attitude is one of the most challenging aspects of any information systems implementation. This is due to the fact that a change in information system can significantly change the manner in which employees engage in their jobs, perform work, and interact with one another. She proposes a conceptual model of the influence of organizational development (OD) intervention on employee readiness, openness, and commitment to information system implementation. Creating a positive employee attitude will increase user participation and a higher level of satisfaction with the ERP system (Guimaraes et al., 2015). When change is not managed properly, it causes employees to suspect and behave against the implementation (Kiran \& Reddy, 2019), ultimately leading to employee resistance to the project (Pabedinskaitè, 2010).

\section{User involvement}

User involvement is another significant factor for a successful ERP implementation. While studying ERP implementations across different eras of the Shanghai Tobacco Corporation, Tan et al. (2020) noted an evolution in perceived influence beginning with only top management was capable of steering ERP implementation and ending with the acceptance that business units (people) were key drivers in an ERP implementation, as well. User involvement ensures that business processes driven by the new ERP are better aligned with the needs of the organization (Chatzoglou et al., 2016). Guimaraes et al. (2015) add that user involvement improves communication with the developers, leading to a better understanding of organizational needs. Involving users in the project leads to increased user satisfaction, which is a critical factor for successful implementation (Shah et al., 2011).

\section{Data quality}

Data quality and data validation are also key factors for a successful ERP implementation, although few literary articles list them as significant factors. Xu (2019) describes data quality as critical for a successful implementation due to the highly integrated nature of ERP systems. Xu concluded that data quality of the ERP systems affects the users' perceived usefulness the information gleaned from ERP system. Data errors can be very costly for organizations (Arachchi et al., 2015). Thus, organizations should ensure there is a clear roadmap for data deployment as it is the core of the data migration journey (Gaur, 2020).

In summary, there are many factors that can influence the success or failure of an ERP implement. The literature clearly indicates that these factors include scope control, human factors, top management support, change management, user involvement, and data quality. However, there are many additional critical success factors identified in previous research with no agreement on which of those factors have the most impact on an ERP implementation. This paper examines five critical success factors identified in the literature and provides a perspective gained from our practical experiences to clarify why these five factors have the most impact on ERP implementations.

\section{Method}

This paper evaluates empirical and theoretical, peer-reviewed articles, and internet research discussing ERP solutions and the critical factors and challenges involved in implementing them. Key terms used in the search for articles were ERP, ERP Implementations, and enterprise resource planning. These key terms were used to search the online literary database at the University of North Alabama and Google Scholar. The results of the search provided dozens of articles, but only research articles written in the past 10 years 


\section{Issues in Information Systems}

Volume 22, Issue 2, pp. 146-156, 2021

were reviewed, which narrowed down the search results considerably. Each research article was then evaluated by both co-authors on this paper for content relevant to the subject matter of ERP implementations, ERP systems, ERP success/failure rates, and factors that are critical to the success or failure of ERP implementations. Any research deemed not relevant to the subject matter was discarded. The remaining research was examined and categorized by the subject matter that was relevant to the study.

In addition to theoretical and empirical research, we draw on our experiences gained from managing ERP implementations to establish additional key success factors that should not be overlooked during implementation. Both co-authors on this paper are working in higher education. From our 23 years working in IT, we have worked with five different ERP systems and managed the conversion and implementation of three of those systems. The first ERP implementation involved the conversion of a home-grown system on the iSeries/400 (formerly known as AS/400) to a packaged software on the same system. The next conversion and ERP implementation was much more complex and difficult to manage as it involved implementing new hardware and technology, as well as the ERP system and data conversion. During this ERP implementation, iSeries/400 IBM hardware and technology was replaced with Oracle hardware and technology. Finally, the latest ERP implementation consisted of converting from an in-house Ellucian Banner 8 ERP system to a cloud hosted, Ellucian Banner 9 ERP system in a MEP'd (Multi-Entity Processing) environment. This ERP implementation presented its own challenges due to the nature of a cloud-hosted environment which requires you to give up certain aspects of technical control, in addition to the nature of an MEP'd environment which does not provide an easy way of setting the standards for shared data.

\section{Five key success factors for ERP implementation}

\section{Project buy-in}

Project buy-in is one of the most important factors contributing to a successful ERP implementation. Buyin means employees are one hundred percent committed to the project, prepared to commit the resources needed to succeed, open to new business process ideas, and prepared to be available and flexible for training. A successful ERP implementation needs the leadership and influence of top management; therefore, buy-in must start at the top of the organization and filter its way down to the functional users. It is important that end users know the project has support from top and middle management in order to fully commit to the project themselves. Vayyavur (2015) suggests that senior management should identify the project as top priority by doing what is required during implementation to make sure all the processes and steps are clear.

From our experience, when top management is perceived as not being fully committed to the project, it is reflected throughout the implementation and is most visible in employee participation and performance. If end-users are under the impression that the leaders of the organization are indifferent to the project's success or failure, some may come to the conclusion that their participation in the implementation is optional. As one can imagine, end-users that have given less than their best effort learning the new software will lead to an inability to successfully perform their daily business processes in the new ERP system. Once this occurs, end-users may stop using the system and revert back to manual processes to accomplish their tasks. Since ERP systems are fully integrated and processes are cross-functional, the absence of one functional area's data will leave other functional areas incapable of successfully completing their business processes in the system.

A good idea is for senior management to hold an employee meeting where they announce the ERP implementation, stress the importance of the project, while acknowledging their commitment to make it a 


\section{Issues in Information Systems}

Volume 22, Issue 2, pp. 146-156, 2021

top priority and allocate the necessary resources needed to successfully complete the project. Middle management should follow this up with their own departmental meetings, providing more details on the project and reiterating the importance of the project and the commitment of management to see the project through from beginning to end.

\section{Change management}

In addition to project buy-in, employee attitude towards the implementation is essential to project success. People that work in Information Technology are accustomed to and expect change as part of the territory that comes with working in the technology field. However, this is not true for employees that work in other functional areas (e.g., HR, Finance, Purchasing). It has been our experience that users typically do not like change and will be resistant when learning of a future ERP implementation. The reality of learning a new software, along with changes that will occur in their day-to-day business processes with the new ERP, otherwise known as business process reengineering, creates stress and uncertainty for the employees. Maintaining a positive attitude among employees is a challenge, but is also critical to successful ERP implementation.

The employees of an organization will be the ones doing the "heavy lifting" during the implementation and employees with a poor attitude will not give their best effort learning, training, and participating in the implementation. During our first experience managing an ERP implementation, employee morale was low and attitudes were less than stellar, including the entire IT department. We were desperate to improve our situation and were looking for a way to spin our attitudes in a positive direction. The book, Who Moved My Cheese? written by Spencer Johnson, was passed around and read by the IT director, ourselves, and most functional team leads. It was amazing to see the difference this simple parable about mice in a maze looking for cheese improved all of our attitudes. Our point is, organizations must find a way, whether it is reading a book or participating in team-building activities, to ensure that employees maintain a positive attitude throughout the implementation.

In the literature, Chaudry (2018) describes organizational development (OD) interventions that influence employees in a manner that makes adapting to ERP implementations easier for them. The interventions are inclusive of management of the relationship with the organization, communication of information regarding the change initiative (implementation), and positive changes in knowledge, skills, behavior, and attitude at the individual level. We have found in our experience that these methods are the key ingredients to successfully implement change. Organizations should:

- Manage the relationship with employees by collaborating with them on the change initiative. Employees and managers should work together on facilitating the resources necessary for the ERP implementation. The importance of this relationship is reflected throughout the implementation and will be most evident in employee participation. Employees that feel they are a part of the project will be more willing to participate in the various activities involved in an implementation, such as training, data validation, and testing.

- Effectively communicate the details of the upcoming implementation such as the timeline and training schedule. Employees should also be kept abreast of the project progress and any setbacks that occur along the way. A lack of communication creates a barrier between management and employees and will affect employee attitude and performance.

- Relate the positive changes in knowledge and skills that comes with learning a new software. Organizations should make sure employees understand they are not just learning a new software; they are also adding to their skillset. Failing to educate employees about their perceived benefits can cause resistance and hamper the implementation (Kiran \& Reddy, 2019). We have noted during our experience with implementations, employees that feel they are adding to their skillset and 


\title{
Issues in Information Systems
}

\author{
Volume 22, Issue 2, pp. 146-156, 2021
}

making themselves more valuable as an employee will be more open and receptive to learning new business processes, in effect creating a more positive attitude towards the implementation.

\section{Employee training}

Employee training is required for any ERP implementation and must be taken seriously as the learning curve for many of the most popular ERP packages is very high. Guimaraes et al. (2015) encourage managers to realize the importance of training end users to use the new system as it leads to more satisfaction and confidence. From our experience managing implementations, we have learned that the sophisticated functionality included in ERP packages requires adequate training from the consultant. The training should not only be adequate, but it should also be the right type of training. Many companies have transitioned to different types of virtual training, with some even offering on-demand training to provide flexibility and cost-savings to organizations, but in our experience, hands-on, in-person training is the better alternative. Virtual training is useful in certain situations, but in order to provide adequate training to users learning a new system, they need dedicated time spent with a trainer in a live test environment. Users who remain in their office at their desk for virtual training will not commit the time and attention needed to learn the functionality of the new system. They will be distracted by interoffice phone calls, emails, and other business tasks instead of concentrating on the task at hand. The training should take place in quiet area, away from the distractions of the office where the employees can focus on the task at hand.

The literature does not address data as it relates to training, but we recommend using a subset of real legacy data to assist in the training process. Users become familiar with the data they use on a daily basis and it is beneficial for them to see how this data evolves through end-to-end processes as opposed to made-up data like customer Mickey Mouse or company XYZ.

\section{Employee participation}

The timeline for ERP implementations can cover anywhere from several months to several years. This requires long-term commitments from employees that consist of numerous training sessions, validating data, and learning new business processes, all while continuing to take care of their normal, everyday work commitments. In order to keep employee morale from declining, it is imperative that management keeps employees engaged in the process of the implementation. After all, the knowledge of the users will play an important role in the ERP implementation. During the implementations that we have managed, we found it beneficial to create a team of cross-functional experts that would meet all throughout the implementation. The team meetings offer an environment conducive to discussing issues with the implementation such as changes to the timeline or training schedule, training issues, data conversion/validation issues, or any other problems encountered with the implementation. The team meetings offer a space for effective crossfunctional collaboration and communication where employees feel they play an important role in the project. The information gleaned from the meetings would prove to be so beneficial, that we would continue to meet post-implementation, transitioning from an implementation team to a user group team.

The literature shows that change management, employee training, and employee participation are all intertwined. Guimaraes et al. (2015) demonstrated that employee training is a significant factor in user participation in the implementation process, while Momoh et al. (2010) state that lack of training and lack of change management can lead to project failure. We have found it imperative that employee participation not be discounted as it can lead to a sense of empowerment for employees which, in turn, leads to improved attitude and motivation, both being critical factors in change management and employee training. 


\section{Issues in Information Systems}

Volume 22, Issue 2, pp. 146-156, 2021

\section{Data validation}

Data validation is not included as a key factor for ERP implementations in the literature very often. However, collecting and analyzing data are the primary goal of an ERP system. During an ERP implementation, users will be asked to validate data that has been converted from the legacy system and cross-walked to the new ERP system. It has been our experience that an organization will never achieve the goal of perfectly clean data from a conversion, but integrity of the data is still critical and very much a key factor for successful ERP implementations. The literature suggests that during an implementation, the organization must be aware of the quality of the data and the way the data is collected (Xu, 2019). Xu further states that data quality definitely has an impact on the success of the implementation. Based on our experiences with data conversion during ERP implementations, we recommend making data validation a top priority for the organization during the conversion phase, and this should start with making sure any crosswalks built for data conversion are correct. Data that is determined to be incorrect as the result of an inaccurate crosswalk is hard to find and usually does not show up until post-implementation. This is because the value in the field is valid according to the available values allowed, but is mismatched because the crosswalk value was incorrect. These types of data errors will show up later in reporting and analysis when huge differences are determined in values pre and post conversion. At this point, cleaning the data will be very time consuming and costly for the organization.

Data validation should consist of more than just running list reports to check for data accuracy. Although this is an important step, the organization should go further and perform additional validity checks on the data. Comparing record counts from the legacy tables and the corresponding tables in the new system is a good way to make sure that all the records in the tables were converted. The organization can also compare legacy totals, such as total sales for a period, to totals in the new system. Once these validations have been done, end-to-end business processes should be executed in a test environment while evaluating the data as each step is completed to ensure that the data produces the desired outcome.

\section{Discussion}

\section{Summary of content}

Research shows there are numerous key factors that are critical to the success or failure of ERP implementations. However, there is no consensus on which key factors have the greatest impact on implementations. Due to substantial financial loss when ERP implementations fail, organizations spend a great deal of time and effort on planning, defining the project scope, project budget, and project timeline. This is understandable as these key factors offer a way to monitor the project and make sure it stays on track. However, the research also shows there are other key factors just as critical to a successful ERP implementation. In order to succeed, the implementation must also have the support of top management, a change management plan, adequate employee training, encouragement of employee participation, and a plan to properly validate the data, as shown in Figure 1. A breakdown within any one of these critical factors can cause the project to go over budget, not finish on time, and ultimately fail. 


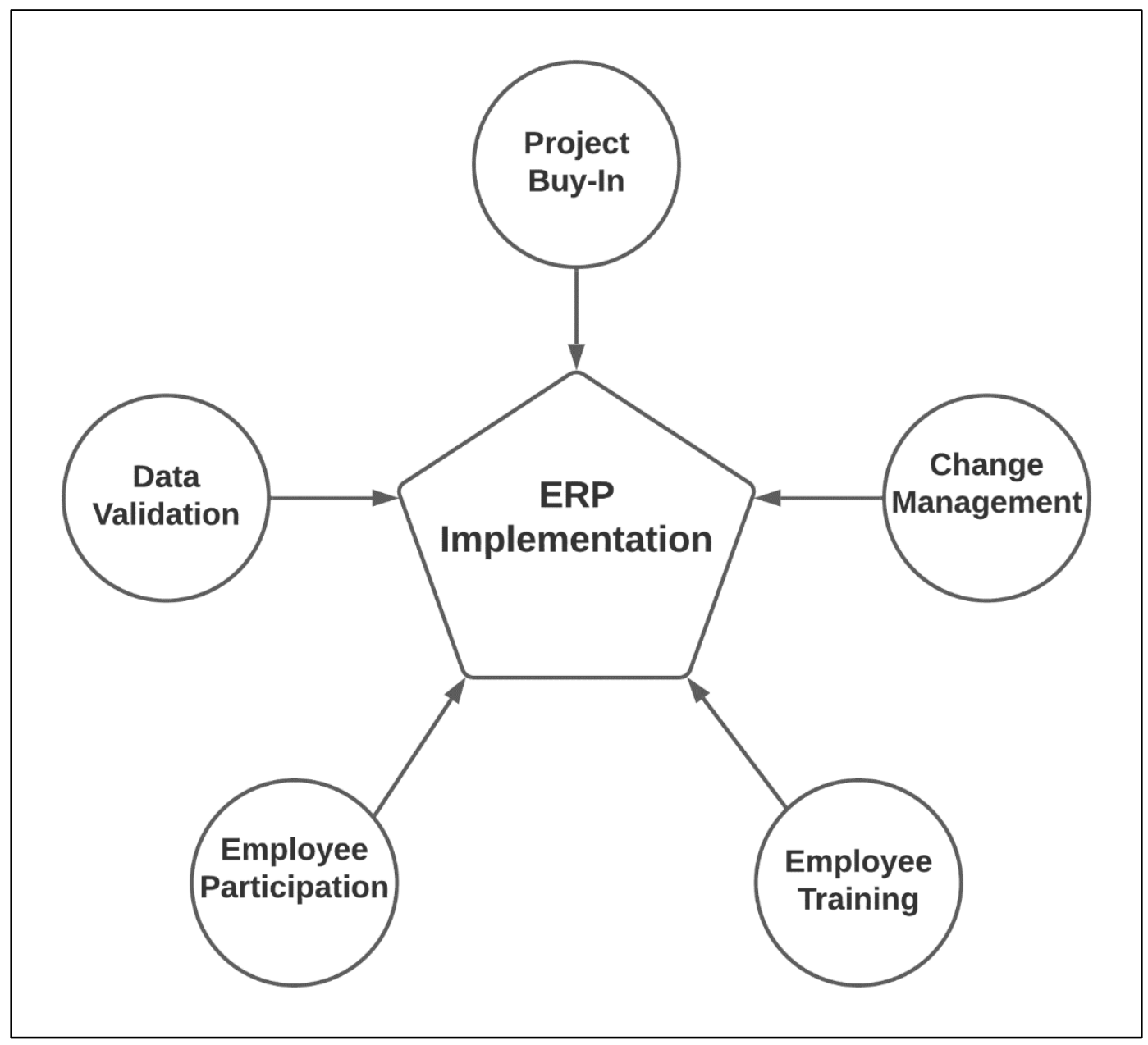

Figure 1: Five Key Success Factors for ERP Implementation

\section{Implications to practice and research}

The objective of this paper was to examine and identify factors that are critical to the success of ERP implementations based on the knowledge that comes with practical experience. This research offers CIOs, IT directors, and project managers useful insights and a unique perspective from practical experience managing ERP implementations, in addition to identifying five factors that are critical to project success from the existing literature. These five factors can be used in practice as a guide to identify the areas in which to allocate resources and help guide organizations in the implementation phase of ERP systems.

\section{Limitations and suggestions for future research}

While the literature review was not limited to a certain type of organization implementing ERP systems, our practical experience managing ERP implementations is limited to those involving higher education. There are many similarities to ERP systems across different types of organizations, but there are also many differences. In the future, a research opportunity would be to focus on comparisons of critical success factors relevant to ERP implementations that are identified in both organizations that offer a service versus organizations that manufacture products to examine the parallels that can be drawn from the two. Future research should consider continuing to examine critical success factors identified by those with practical experience implementing ERP systems, as well. This type of research could help in forming some type of 


\section{Issues in Information Systems}

Volume 22, Issue 2, pp. 146-156, 2021

consensus on which factors have the most impact on ERP implementations, leading organizations to focus more resources in these areas.

\section{References}

Amini, M., \& Safavi, N. S. (2013). Review paper: Critical success factors for ERP implementation. International Journal of Information Technology \& Information Systems, 5(16), 1-23.

Arachchi, S. M., Chong, S. C., \& Madhushani, A. G. I. (2015). Quality assurance and quality control in ERP systems implementation. American Scientific Research Journal for Engineering, Technology, and Sciences, 11(1), 70-83.

Biel, J. (2020, July 15). 50 critical ERP statistics: 2020 market trends, data and analysis. http://www.netsuite.com/portal/resource/articles/erp/erp-statistics.shtml

Chatzoglou, P., Chatzoudes, D., Fragidis, L., \& Symeonidis, S. (2016). Critical success factors for ERP implementation in SMEs. Proceedings of the Federated Conference on Computer Science and Information Systems, 8, 1243-1252.

Chaudhry, S. (2018). Managing employee attitude for a successful information system implementation: A change management perspective. Journal of International Technology and Information Management, 27(1), 58-90.

Gaur, M. (2020). ERP migration challenges and solution approach focused on SAP customers. International Journal of Advanced Research in Computer Science \& Technology, 8(3), 15-17.

Guimaraes, T., Armstrong, C., de Oliveira Neto, J. D., Riccio, E. L., \& Madeira, G. (2015). Assessing the impact of ERP on end-user jobs. International Journal of the Academic Business World, 9(1), 1122.

Jordan, E. (2018, May 4). 4 valuable lessons from major ERP fails. https:/www.mbtmag.com/erp/article/13228432/4-valuable-lessons-from-major-erpfails\#: :text=However\%2C\%20it\%20can\%20be\%20easy,percent $\% 20$ of $\% 20$ ERP $\% 20$ projects $\% 2$ 0fail

Kiran, T. S., \& Reddy, A. V. (2019). Critical success factors of ERP implementation in SMEs. Journal of Project Management, 4(4), 267-280.

Momoh A., Roy, R., \& Shehab, E. (2010). Challenges in enterprise resource planning implementation: State-of-the-art. Business Process Management Journal, 16(4), 537-565.

Mutsaddi, S. (2020, July 14). ERP systems: Understanding the silo effect. https://medium.com/@mutsaddi/erp-systems-understanding-the-silo-effect-e14b559441ad

Pabedinskaitè, A. (2010). Factors of successful implementation of ERP systems. Economics and Management, 15, 691-697.

Saxena, D., \& McDonagh, J. (2019). Evaluating ERP implementations: The case for a lifecycle-based interpretive approach. Electronic Journal of Information Systems Evaluation, 22(1), 29-37. 


\section{Issues in Information Systems}

Volume 22, Issue 2, pp. 146-156, 2021

Shah, S. I. H., Khan, A. Z., Bokhari, R. H., \& Raza, M. A. (2011). Exploring the impediments of successful ERP implementation: A case study in a public organization. International Journal of Business and Social Science, 2(22), 289-296.

Sternad, S., \& Bobek, S. (2012). Acceptance of ERP solutions in maturity use phase: Key influence factors for SAP and Microsoft Dynamics NAV. International Journal of Productivity Management and Assessment Technologies, 1(3), 18-44.

Tan, B., Pan, S. L., Chen, W., \& Huang, L. (2020). Organizational sensemaking in ERP implementation: The influence of sensemaking structure. MIS Quarterly, 44(4), 1773-1809.

Vayyavur, R. (2015). ERP implementation challenges \& critical organizational success factors. International Journal of Current Engineering and Technology, 5(4), 2759-2766.

$\mathrm{Xu}, \mathrm{H}$. (2019). ERP implementation satisfaction - A data quality approach. Journal of Technology Research, 8, 1-16. 